\title{
Preface. Current Issues in Ethics
}

\author{
Magdalena Holy-Luczaj \\ University of Information Technology \\ and Management in Rzeszow, \\ Poland \\ e-mail:mholy@wsiz.rzeszow.pl
}

\begin{abstract}
:
This interdisciplinary volume consist of papers on various problems in contemporary ethics. It presents the following issues: equalizing the level of positive liberty, the phenomenon of human cooperation, ethical questions related to artificial intelligence, extending ethical obligations toward artifacts, and soteriological threads of alienation criticism of religion.

Keywords: ethics, new trends, moral relevance, moral considerability.
\end{abstract}

The major task of ethics is to address questions related to moral dimensions of the most pressing problems in today's world. New controversies arise mainly due to the development of science and technology. We face dilemmas which past generations didn't have to deal with. Thus, we have to investigate new problems that are to be identified at the crossroad of ethics and bio, computer and industrial science, as well as technical knowledge. This requires also use the results of empirical research to lay out new arguments on the grounds of philosophy. Furthermore, our approach to ethical problems is shifting from strongly anthropocentric to posthuman and non-anthropocentric. In result, ethicists reframe the question of who belongs inside a circle of moral relevance. The novelty of research in ethics, however, does not mean that scholars turned away from the heritage of history of philosophy. On contrary, they seek inspirations in classic theories, intending to revisit them and adapt to current problems.

This broad scope of considerations in ethics as well as a variety of problems and new approaches is reflected in contributions to this volume of Studia Humana. The first article, "An Analysis of the Equal Freedom", investigates selected issues related to the postulates of equalizing the level of positive liberty. Its author, Andrzej Stoiński, reminds us that classic understanding of individual freedom referred to as a negative ("freedom from"), identified with a lack of compulsion, is in the opposition to the so-called positive liberty ("freedom to"). The latter is usually defined as an ability related to the concept of power. The postulate of equality in "freedom to" can justify conducting a social redistribution of goods. Thus, Stoiński examines the cases of voluntary and compulsory donation in order to present consequences of a compulsory expansion of the scope of positive liberty.

In the next paper, "Selfishness and Cooperation: Challenge for Social Life", Konrad Szocik and Stig Lindberg argue that cooperation is a great challenge for natural selection. Some scholars assume that cooperation could not evolve within the framework of natural selection. It is undeniable 
that natural selection, at least at the individual level, favors selfishness and defectors. Nonetheless, this selfish tendency does not necessarily imply that cooperation could not evolve by means of natural selection. Drawing upon this assumption, Szocik and Lindberg specifically acknowledge certain basic challenges for the evolution of the human ability to cooperate at the level of large groups. They discuss topics such as the human ability for "super cooperation", the importance of repetition and reputation, and Multilevel Selection Theory as the basic mechanisms of evolution of cooperation.

The paper "Selected Ethical Issues in Artificial Intelligence, Autonomous System Development and Large Data Set Processing" deals with the dilemmas that due to development of information technology and its industrial adaptation, have become the real problems of the contemporary world and not only the ground for the plot of science-fiction literature and films. Paweł Zgrzebnicki shows us that, on one hand, these issues are related to an unprecedented scale on which computational algorithms are currently used as well as a level of complexity of mutual connections; on the other hand, these are linked to their autonomous behavior. States, industry, and users themselves demand formulation of understandable ethical categories and determination of transparency standards and legal norms for these algorithms' functioning in the near future. For this reason, he focused on three areas: determining acceptable goals that can be pursued by an autonomous algorithm or a device using this algorithm, understanding the decisions made by artificial intelligence objects and making supervision over their actions possible.

The paper "Artifacts and The Problem of Ethical Extensionism - Selected Issues" addresses the problem of extending ethical obligations toward material things, which we use every day. In the first part I - honored to edit this volume of Studia Humana - reconstruct current approaches to the problem of the metaphysical and ethical status of artifacts. Next, I intend to unpack the suppositions that are steering the debate on moral status and expanding ethical obligations of human beings toward nonhumans that has been going on for several decades. Arguments for including different animal species, plants, other living organisms, and finally inanimate entities in the boundaries of ethics have successively appeared in numerous works dealing with this issue. Now it is worth establishing possible grounds for extending human moral obligations toward artifacts as beings, which status can be improved or deteriorated through human activity. The core part of the article analyzes ethical implications of the following issues: using artifacts, their production, purchase, and sale of artifacts, and the post-use period.

The last paper by Jowita Guja, "Salutary meanings of sublimation. Selected soteriological threads of alienation criticism of religion", look into a few soteriological threads of alienation criticism of religion, whose feature is the creation of a new autonomous and transgressive subject. Guja has focused on the presentation of this subject using Nietzsche's philosophy perceived from a Freudian point of view. According to her, within this framework, our choices can be described as authentic if they are ultimately determined by a degree of our involvement in them and by our awareness of responsibility. The representatives of the alienation perspective more and more often write about a necessity of real, secular faith whose verification would be an explicit proclamation and in the first place acting in accordance with it. Thus, she concludes, our authenticity can only be proved by our practice.

I wish to thank all of the contributors for their outstanding papers, which, I believe, will be useful and inspiring for our readers. 